\title{
A REAL FINALIDADE DO TRABALHO E A DESMO- TIVAÇÃO DO SER HUMANO
}

\section{THE REAL PURPOSE OF THE WORK AND THE DE- MOVATION OF THE HUMAN BEING}

Jailsom Pereira Alves ${ }^{1}$

Resumo: Este artigo analisa tisfação não apenas profissional, e aponta, sob a luz da Trilogia mas principalmente pessoal. AfiAnalítica - idealizada pelo pional de contas, é através dele que neiro Norberto Keppe, as razões iremos realizar os nossos sonhos. pelas quais o trabalho deixou de No entanto, o que se percebe é ser uma atividade agradável ao uma insatisfação pessoal muito ser humano. Como veremos, de grande. A falta de interesse e a acordo com Keppe, é no trabadesmotivação do ser humano se lho que passamos a maior parte devem ao fato de o trabalho ter se do nosso tempo: abrimos mão tornado deturpado em sua finalide momentos com nossos familiares e amigos em prol do nosso dade. Diante disso, é imprescindível que se conheça a essência crescimento profissional. Sendo do trabalho para o ser humano, assim, é fundamental que nosso de modo a modificar seu pensatrabalho nos proporcione momento e suas atitudes rumo ao tivação e, como conseqüência, bom, ao belo e à felicidade.

sentimentos de felicidade e sa-

1 Especialista em Gestão de Conflitos: Psico-Sócio-Patologia

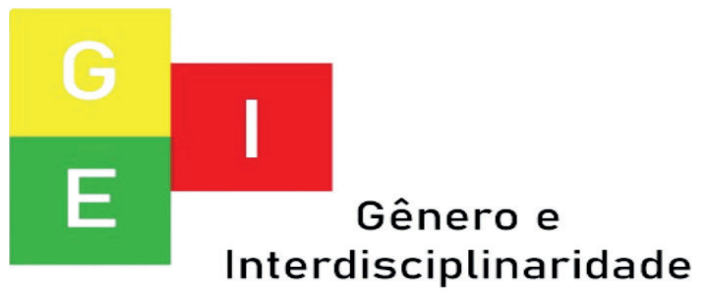


ISSN: 2675-7451

Vol. 02 - n 03 - ano 2021

Editora Acadêmica Periodicojs

Palavras-Chave: Trabalho. Desmotivação. Psico-Sócio-Patologia. Bom. Belo.

Abstract: This article analyzes and points out, in the light of the Analytical Trilogy - idealized by the pioneer Norberto Keppe, the reasons why the work is no longer a pleasant activity to the human being. As we will see, according to Keppe, it's at work that we spend most of our time: we give up on moments together with our family and friends for our professional growth. Therefore, it is fundamental that our work provides us with motivation and, as a consequence, feelings of happiness and satisfaction, not only professional, but mainly personal. After all, it is through it that we will realize our dreams. However, what is perceived is a very great personal dissatisfac- tion. The lack of interest and the human being demotivation are due to the fact that the work has become distorted in its purpose. Faced with this, it's essential to know the essence of work for the human being, in order to change his thinking and his attitudes towards good, beautiful and happiness.

Keywords: Work. Demotivation. Psico-Socio-Pathology. Good. Beautiful.

\section{INTRODUÇÃO}

A partir do Século XX, sobretudo após a Segunda Guerra Mundial, o Brasil começou a atravessar um processo de industrialização significativo. Passaram a se instalar no país inúmeras empresas com o objetivo de atender às necessidades básicas de consumo da população. E isso

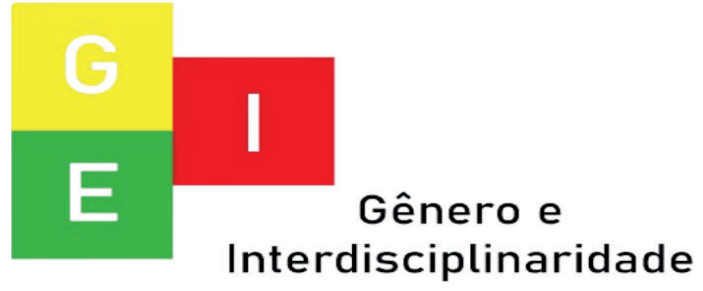


ISSN: 2675-7451

Vol. 02 - n 03 - ano 2021

Editora Acadêmica Periodicojs

só ocorreu através de incentivos políticos e econômicos. Com essas indústrias diversos empregos foram criados. Nisso, o país foi crescendo e se desenvolvendo a cada dia.

Diante de todo esse processo de industrialização, foi preciso criar leis trabalhistas a fim de garantir direitos a todos os empregados. A partir daí, as exigências e as cobranças por resultados e lucros também passaram a aumentar de tal maneira, que as pessoas sem perceber, começaram a dedicar mais horas às atividades no trabalho e poucas horas ao lazer. Com o passar do tempo isso acabou levando à desmotivação pessoal e pouquíssimos momentos agradáveis (lazer) seja com familiares ou amigos. Mediante tais fatos, como veremos, de acordo com Norberto Keppe, tudo isso indica que o trabalho deixou de ser prazeroso na me- dida em que se tornou deturpado em sua finalidade. Portanto, ao estudar a obra de Norberto Keppe, levantamos algumas hipóteses: o trabalho foi modificado na sua finalidade; o verdadeiro trabalho depende da inteligência e do sentimento, pois são indissociáveis

\section{REFERENCIAL TEÓRICO}

Sabe-se que é através do trabalho que conseguimos manter as necessidades básicas de nossa família: alimentação, vestimenta, educação, saúde, etc. Ou seja, sem ele, viveríamos em situação de grande precariedade e necessidade. Isso porque o trabalho é fundamental para a realização do ser humano em todos os aspectos, tanto que passamos a maior parte do tempo trabalhando, deixando de lado momentos que poderíamos passar ao lado

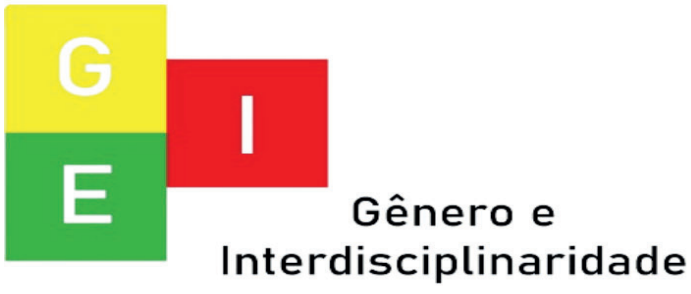


ISSN: 2675-7451

Vol. 02 - n 03 - ano 2021

Editora Acadêmica Periodicojs

de nossas famílias e amigos.

Com toda essa importância que passou a ter o trabalho, o ser humano deixou de levar em conta sua satisfação e motivação que, como afirma Norberto Keppe, dependem de três condições: (a) o trabalho deve ser bom para a humanidade e, portanto, para cada um que trabalhe; (b) deve ser real, ou melhor, deve ser feito com a finalidade de realizar o desenvolvimento humano e social e; por fim, (c) deve proporcionar beleza para a vida da pessoa que o realiza (KEPPE, 2003, p. 172).

De acordo com Keppe (2003), o ser humano precisa saber que quanto mais ele vive, mais importante é para a sociedade; seu trabalho deverá ser ininterrupto enquanto viver nossa vida se identifica à atividade, e segundo o que tivemos desenvolvido, assim será nossa eternidade.
Não basta apenas e tão somente ter um trabalho, é importante que aquela atividade remunerada tenha uma relevância não só para a pessoa, mas para todos à sua volta, de modo a proporcionar motivação e satisfação pessoal. O trabalho deve desenvolver a todos na sua integralidade. Segundo Norberto Keppe (2003, p. 172):

O trabalho precisa ser útil, correto e esteticamente aproveitável, para ser bom ao ser humano; [...] uma atividade qualquer tem de ajudar no crescimento material e espiritual do homem - caso contrário produzirá distorções na sua personalidade.

Em outras palavras, o trabalho tem que ser algo que irá transformar a vida do indivíduo; deve ser algo benéfico não ape-

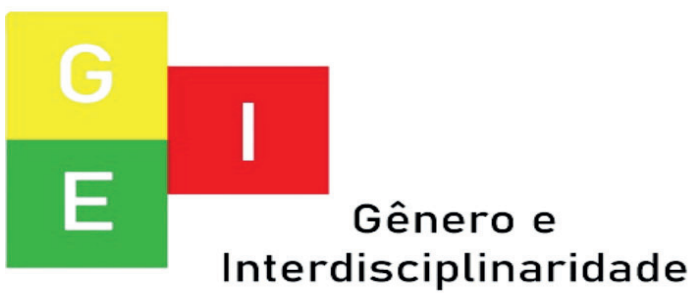


ISSN: 2675-7451

Vol. 02 - n 03 - ano 2021

Editora Acadêmica Periodicojs

nas para ele, mas para a sociedade na qual está inserido. Para tanto, é fundamental que haja um equilíbrio financeiro e pessoal para assim manter a sua essência. Conforme ensina Norberto Keppe (2003, p. 173):

Se a ação em si é o fundamento do equilíbrio humano e social, não podemos nos esquecer que o trabalho explorador é também causa de todos os males psicossociais. É o que está acontecendo agora com o crescimento assustador de todas as doenças, psíquicas e orgânicas.

Ou seja, se a ação em si é a base do equilíbrio humano e social, não podemos nos esquecer de que o trabalho explorador e que visa apenas o lucro, pode ser a causa do estresse e da desmotivação para que o homem de- senvolva bem o seu trabalho.

Através de seus estudos

e pesquisas, Keppe integrou a ciência à teologia e à filosofia, pois todas caminham juntas em prol do mesmo objetivo: a consciência de um mundo melhor, onde a harmonia, o afeto e o desenvolvimento possam ser vividos em sua intensidade. Segundo o autor:

A teologia deveria mostrar as maravilhas de Deus, enquanto a filosofia, a beleza que o homem teria obrigação de ver, e a ciência a recusa que realizamos a tudo isso; se algum desses campos deixa de ver tais dificuldades é porque está falhando em seus objetivos. A ciência tem a função de corrigir ou mesmo de compreender o pensamento filosófico e o teológico; cada um desses setores teria a finalidade de esclarecer

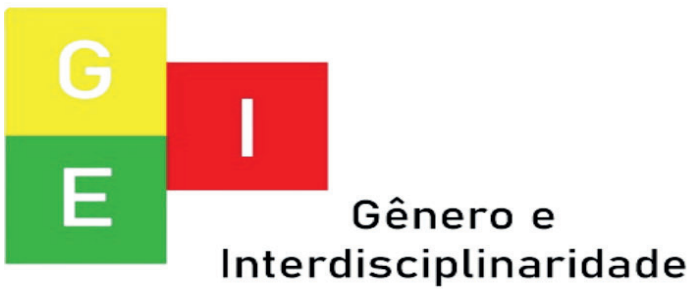


ISSN: 2675-7451

Vol. 02 - n 03 - ano 2021

Editora Acadêmica Periodicojs

e ampliar os outros, como a única maneira de haver vida e desenvolvimento. Para que a fé não falhe é fundamental haver um raciocínio saudável, que por sua vez depende da existência do fideísmo quando um dos dois é negado o indivíduo se desequilibra. Se apenas a verdadeira fé e a razão não se opõem, como é possível intercambiar uma a outra se o indivíduo aceitar o desenvolvimento? Esse é o único meio de haver um total crescimento científico (KEPPE, 1999, p. 14).

Com base na citação acima, pode-se dizer que as três ciências ali colocadas foram unificadas pelo fato de uma estar diretamente atrelada à outra. Uma complementa a importância da outra de modo que consegue responder algumas questões sobre as relações entre o trabalho e o ser humano. Conforme Norberto Keppe (2005, p. 16):

$\mathrm{O}$ centro essencial da pessoa é formado pelo amor, pela razão e estética, mas devido aos fatores principalmente da teomania, megalomania e inveja, esse ponto central é reduzido e o homem passa mais a um estado de não-ser - e daí em diante começa a representar, criando uma existência fictícia. Qual é, por exemplo, a importância da economia para a essência humana? Qual o valor de um grande poder neste mundo, se não for usado para a felicidade de todos? Temos de admitir que o verdadeiro bem só poderia ser o definitivo. $\mathrm{O}$ homem faz uma re-

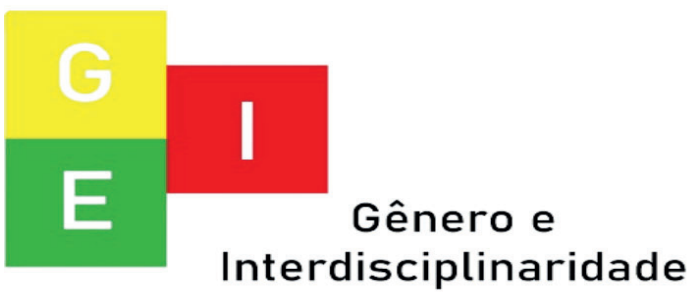


ISSN: 2675-7451

Vol. 02 - n 03 - ano 2021

Editora Acadêmica Periodicojs

presentação do que é é o motivo que nos move para de-

o não-ser, para tentar ser - o que o torna impossibilitado de viver a realidade.

Segundo Keppe (2005), a essência da pessoa é o amor, a razão e a estética, porém há fatores que reduzem drasticamente essa essência. É fundamental que o ser humano perceba a importância da economia e do seu trabalho para toda a sociedade: não apenas para o seu patrão, pois isso o levará à desmotivação e, consequentemente ao estresse.

Quanto a isso, outros fatores importantes apontados por Norberto Keppe (1987) como pilares do estresse e desmotivação do ser humano em relação ao seu trabalho são a resistência e a inversão. De acordo com o autor, a forma como as pessoas tendem a se comportar é secundária no processo vital; o ponto principal terminadas ações. É o que acontece quando, por exemplo, uma pessoa procura o roubo, a luxúria, o poder social; ela acredita que está em busca de algo que lhe trará grande felicidade e, portanto, está realizando uma inversão; a cada nova experiência aparece outra decepção, motivo pelo qual deverá perceber o processo invertido que está fazendo.

Sobre o assunto Keppe (2013) ressalta que o campo da psicoterapia seguiu um caminho contrário ao que deveria ser - em lugar de incentivar a percepção dos erros, procurou “resolver" os problemas, isto é, escondê-los, para alimentar a megalomania e a arrogância; é por este motivo que na maior parte das vezes todo aquele que se submete a um processo de terapia acaba se tornando muito mais arrogante e resistente do que era.

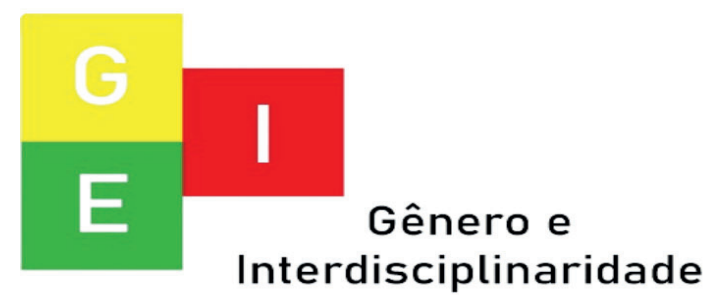


ISSN: 2675-7451

Vol. 02 - n 03 - ano 2021

Editora Acadêmica Periodicojs

O espírito, por si, não foi ofuscado, mas deixou de captar toda a beleza e bondade do Criador, por ter invertido sua função, colocando os sentidos na base, como fonte de todo conhecimento (aristotelismo e tomismo). Desde que Cristo trouxe-nos a revelação, o ser humano tem feito tudo para provar que ele não estava certo. $\mathrm{O}$ pensamento filosófico, a ciência atual e até mesmo a teologia têm essa preocupação fundamental, a ponto de alguns religiosos e parapsicólogos atuais terem a ousadia de afirmar que o próprio Deus (Jesus) poderia ter tido visões e ser doente - e não eles (os eclesiásticos e pseudocientistas) estarem projetando no filho do Criador a sua psicopatologia (KEPPE, 2013).

O ser humano não tem consciência e não aceita o fato de estar cometendo o pecado original durante toda a sua existência: insiste em atitudes que vão contra o Criador, à vida, ao amor e à própria felicidade; não quer receber o que é bom (o incrível gozo que há no ser divino); se recusa a usufruir dos mais belos sonhos por dois motivos: resistência e inversão (KEPPE, 2013) podendo ocasionar:

(a) baixa resistência à frustração: característica do indivíduo que se aborrece facilmente; (b) ameaças constantes: pessoas que se sentem intimidadas, gerando atitudes de recuo, de afastamento; (c) competitividade: pretender uma coisa simultaneamente com outra pessoa; (d)

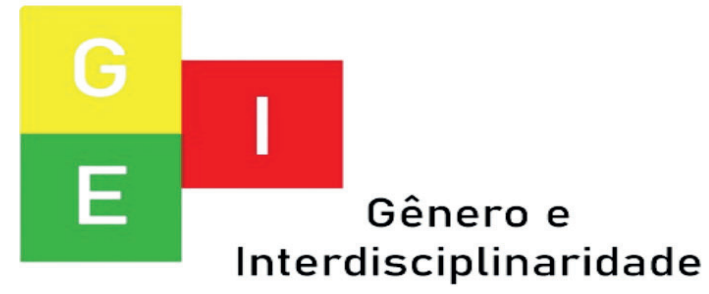


ISSN: 2675-7451

Vol. 02 - n 03 - ano 2021

Editora Acadêmica Periodicojs

falta de tempo para si mesmo: Trata-se do indivíduo que não consegue se organizar, se programar, para que o seu tempo seja bem administrado; (e) ansiedade constante: quando o indivíduo apresenta um comportamento aflitivo ligado a uma sensação constante de perigo; (f) baixa estima: pessoas que não se gostam, não se valorizam; (g) estresse de final de carreira: ocorre, eventualmente, quando o indivíduo não se preparou psicologicamente para essa etapa da sua vida (CARVALHO; OZILÉIA, 2001, p. 125).

Todavia existem diversos fatores capazes de causar desmotivação e estresse no trabalho, entre os quais a falta de tempo para si mesmo, para fazer as coisas que realmente gosta e assim, poder descansar verdadeiramente.

O mais importante de tudo é organizar uma estrutura de trabalho que seja, todo ele, um benefício geral, do indivíduo e da sociedade - eliminando pouco a pouco toda atividade egoísta, de lucro imediato, que só vem servindo para destruir a natureza, e levando o homem para as doenças psíquicas e orgânicas. Só neste caso é que podemos dizer que o dinheiro é supérfluo. O ser humano deve tentar ser útil e não daninho para a humanidade, e para si próprio, como decorrência (KEPPE, 2003, p. 50).

De acordo com Norberto Keppe (2003), é fundamental que o trabalho seja algo saudável

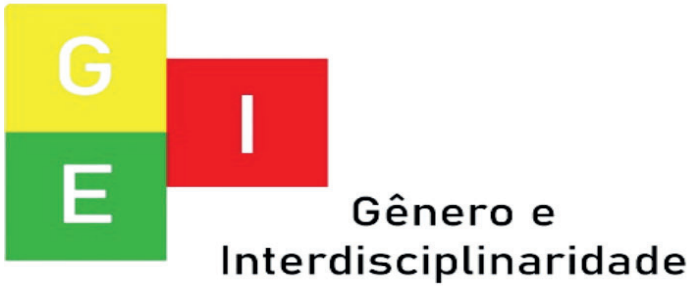


ISSN: 2675-7451

Vol. 02 - n 03 - ano 2021

Editora Acadêmica Periodicojs

para todos de uma forma geral, não só para o trabalhador em si, mas para toda a sociedade. Deve haver prazer na execução daquela atividade. Contudo, após o trabalho, o ser humano também deve ter outras atividades que lhe proporcionem bem estar, alegria, satisfação, motivação, pois caso contrário acabará adquirindo doenças psíquicas e orgânicas, que prejudicarão seu rendimento no trabalho, além de ocasionar uma série de outros problemas.

A única maneira de fazer com que o ser humano aceite trabalhar com prazer é realizar algo para si mesmo e para a sociedade. Sabemos que a finalidade do trabalho atual é a de fornecer lucro financeiro imediato para os proprietários das indústrias, firmas comerciais, fazendas, e para os governos, quando eles também são donos das empresas. Temos de desinverter tal situação, e levar o homem a agir em seu próprio interesse. Este é o primeiro passo (KEPPE, 2003, p. 50).

Conforme relata Norberto Keppe (2003), é fundamental que o ser humano tenha prazer em realizar seu trabalho e perceba o quanto ele é essencial para a sociedade, algo que não acontece nos dias atuais, pois o objetivo principal do trabalho é dar lucros às empresas a qualquer custo, sem que haja alguma motivação para tal.

Trabalhar com alegria e entusiasmo, favorece não apenas o próprio indivíduo, mas a própria empresa. Devido a isso, Keppe criou um novo conceito de empresas, que são as empresas trilógicas, onde a base é a honestidade e não a exploração dos

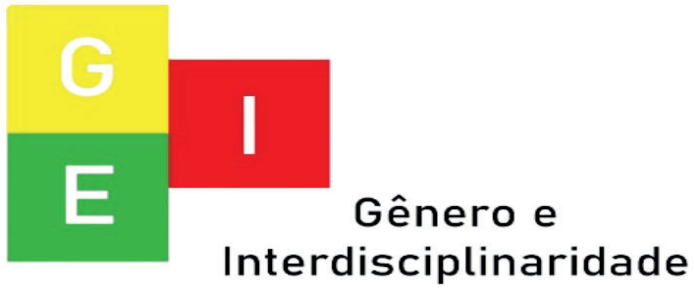


ISSN: 2675-7451

Vol. 02 - n 03 - ano 2021

Editora Acadêmica Periodicojs

funcionários, pelo contrário, eles são valorizados e entendem verdadeiramente seu papel dentro da empresa.

A finalidade das Empresas Trilógicas é Corrigir a Sociopatologia da Humanidade. As Empresas Trilógicas são um conjunto de firmas que procuram unificar, simplificar e desenvolver o trabalho do ser humano e distribuir o dinheiro de acordo com a capacidade e o trabalho de cada um. É bem o contrário do capitalismo e socialismo que colocam o trabalhador sob dependência do capital e do poder social. Desta maneira, organizam-se dois grupos doentios: os que trabalham e vivem totalmente alienados, sem nenhuma participação social; e os que retêm o poder econômico e social e desenvolvem enorme megalomania e narcisismo, não raras as vezes entrando em psicose grave. (ideias de grandeza e delírios persecutórios) (KEPPE, 1990, p 240).

É através das empresas trilógicas que o trabalho ocupará sua verdadeira finalidade. A partir daí, os indivíduos começarão a perceber sua importância dentro de uma organização; receberão por aquilo que realmente fizerem com muita qualidade e responsabilidade; trabalharão mais motivados, com afinco, dedicação, prazer. Consequentemente trarão maiores resultados positivos para a empresa; seus valores serão reconhecidos e receberão verdadeiramente por aquilo que produzirem.

Em uma empresa triló-

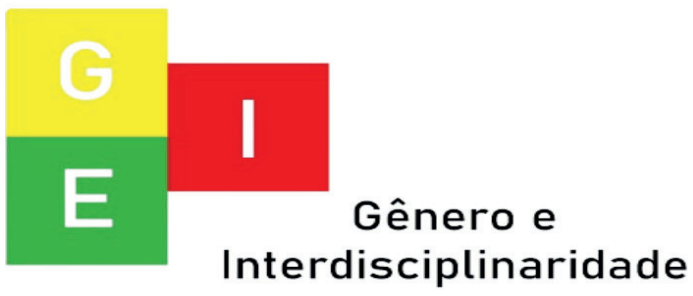


ISSN: 2675-7451

Vol. 02 - n 03 - ano 2021

Editora Acadêmica Periodicojs

gica ser humano só recebe por aquilo que seu trabalho verdadeiramente rende, nem mais, nem menos; isso permite que as pessoas tenham maior conscientização do seu papel sem ficar sem dinheiro, tampouco passar necessidade.

A empresa trilógica é a maior fonte de consciência capaz de corrigir a estrutura sociopatológica e psicopatológica. $\mathrm{O}$ tão falado problema de desemprego pode também ser resolvido, desde que a sociedade passe a girar em torno da ação, pois desse modo o capital não seria visto mais como o seu principal propulsor. Com esta modificação os governos de cada país ficariam livres para cuidar de outras questões. Notem bem que as empresas trilógicas são comandadas, por to- dos os que trabalham nelas (KEPPE, 1991, p. 253).

Diante da afirmação acima, se percebe que é através da empresa trilógica que será possível corrigir problemas sociopatológicos e psicopatológicos que acometem os seres humanos de um modo geral. Desta forma, não haveria desemprego, pois a sociedade iria em busca de ações e o capital não seria visto como algo fundamental para uma empresa, mas sim, inclusive, como um obstáculo para seu crescimento. Na empresa trilógica não existe hierarquia baseada no capital investido, apenas nas funções. Todas as pessoas participam ativamente das decisões da empresa e têm o interesse de se unir e fazer um bom trabalho. $\mathrm{Na}$ passagem abaixo, Norberto Keppe (2003, p. 207) explica bem a

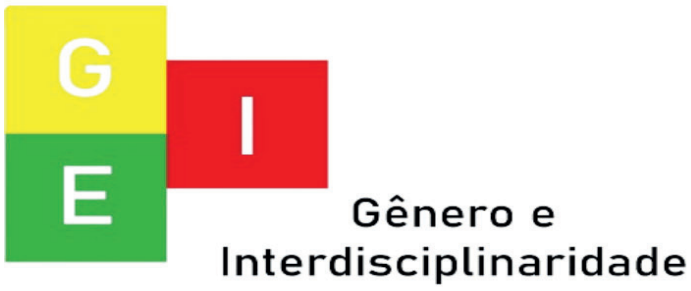


ISSN: 2675-7451

Vol. 02 - n 03 - ano 2021

Editora Acadêmica Periodicojs

diferença entre uma pessoa pato-

lógica e uma pessoa sã:

$\mathrm{O}$ indivíduo muito patológico pensa só em si mesmo, enquanto que o saudável pensa mais na empresa; o primeiro tem mentalidade capitalista ou socialista, e o segundo trilógica. Assim sendo, criam automaticamente dois grupos, ou seja, os que trabalham (a grande maioria do povo) e os que mandam (os que são mais desonestos e incapazes). Podemos dizer que toda organização que possui esses dois tipos de pessoas é profundamente enferma; só este motivo é suficiente para ver que as estruturas econômicas atuais não terão bom resultado. Os loucos não podem dirigir o que quer que seja, por muito tempo, sob pena de provocarem sua bancarrota.

O referido autor também completa ao afirmar o seguinte: Uma pessoa muito doente acaba sendo egoísta e só pensa em si, em seus próprios problemas e se fecha em seu mundo, enquanto aquela que tem boa saúde pensa mais na empresa, no quanto ela pode melhorar seu desempenho e, assim, contribuir para o crescimento da mesma. Ou seja, a partir do momento em que o indivíduo "dá valor ao trabalho, se dá bem com qualquer um deles, tem sucesso em toda atividade; aperfeiçoa e melhora todo o ambiente em que vive, bem como, passa a realizar algo profundamente transcendente". (KEPPE, 2007, p. 107)

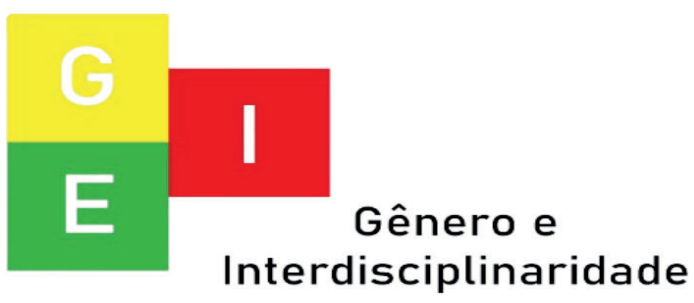


ISSN: 2675-7451

Vol. 02 - n 03 - ano 2021

Editora Acadêmica Periodicojs

satisfação.

Sendo assim, ao valori-

zar e compreender a essência do

\section{CONSIDERAÇÕES FINAIS}

seu trabalho, o indivíduo passa a

ser um profissional melhor e com

muito mais êxito em sua ativida-

de. Essa postura é extremamente

nobre e transformadora. Ou seja,

"no momento em que o ser hu-

mano comece a sentir seu traba-

lho como sendo uma forma de

alegria, pelo alcance que tem e

pelo bem-estar em se desenvol-

ver, toda a questão trabalhista

será resolvida" (KEPPE, 2007, p.

108).

Os problemas sempre farão parte da vida do ser humano, contudo, segundo Norberto Keppe, ainda há esperança no caso do trabalho. Basta que o indivíduo entenda a essência deste e sua importância em todos os aspectos, pois só assim terá a capacidade de realizar suas obrigações com muito mais alegria e

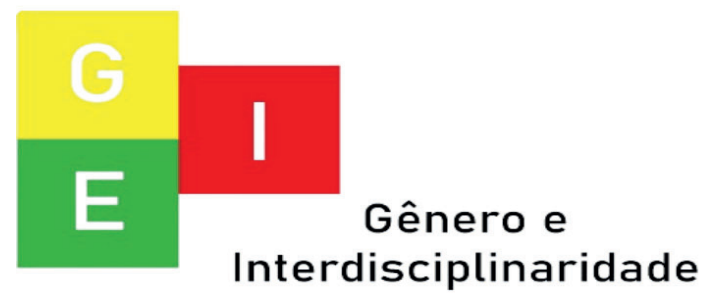
vida do ser humano. É a partir dele que se conquista uma condição financeira melhor, a ampliação do conhecimento, satisfação pessoal e desenvolvimento econômico. Contudo, como vimos no conteúdo aqui colocado e discutido, nem todas as pessoas conseguem atingir tais objetivos. $\mathrm{O}$ indivíduo passa boa parte da sua vida trabalhando a fim de garantir uma vida melhor para si e para sua família, além da sensação de estar sendo útil para o desenvolvimento do país. No entanto, para que possa usufruir dos benefícios citados e continuar tendo um trabalho agradável, satisfatório, compensador, motivador ele necessitará se conscientizar da inversão. Isso 
ISSN: 2675-7451

Vol. 02 - n 03 - ano 2021

Editora Acadêmica Periodicojs

porque, mesmo em condições boas de trabalho, sem exploração como comentado no decorrer deste artigo, grande parte dos indivíduos tem resistência ao trabalho por esta questão patológica da inversão.

Mediante tais fatos, conclui-se que, para se sentir motivado o ser humano precisa gostar do que faz. Num primeiro passo, uma atitude afetiva poderia modificar sua situação profissional, até que toda estrutura social fosse transformada em um plano agradável. Mas, isto só poderá ser realizado através da ação trilógica (realizar o bem, o real e o belo). Conforme afirmou Norberto Keppe (2003, p. 268) quanto mais o ser humano se conscientizar (a realidade) maiores serão suas possibilidades de modificar toda a maneira de trabalhar, de modo a se sentir motivado e tornar sua vida extremamente prazerosa. Tudo dependerá do esforço deste em mudar atitudes enraizadas pela sociedade capitalista, rumo à conscientização do bom, do real e do belo (Trilogia Analítica).

\author{
REFERÊNCIAS BIBLIO- \\ GRÁFICAS \\ CARVALHO, Antonio Vieira de; \\ OZILÉIA, Clen Gomes. Admi- \\ nistração de recursos humanos. 2 \\ ed. São Paulo: Pioneira, 2001.
}

KEPPE, Norberto Rocha. Trilogia analítica. $1^{\mathrm{a}}$ ed. São Paulo: Próton Editora, 2013.

- Bíblia trilógica.

1 ed. São Paulo: Próton Editora, 2007.

. O homem interior. 1 ed. São Paulo: Próton Edi-

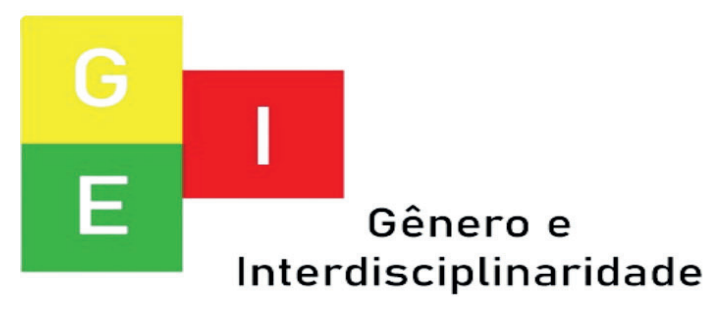


ISSN: 2675-7451

Vol. 02 - n 03 - ano 2021

Editora Acadêmica Periodicojs

tora, 2005.

Trabalho \& capi-

tal. 3 ed. São Paulo: Próton Edi-

tora, 2003.

Metafísica trilógi-

ca: a libertação do ser. 2 ed. São

Paulo: Próton Editora, 1999.

- Sociopatologia:

bases para a civilização do $3^{\circ} \mathrm{mi}$ -

lênio. São Paulo: Próton Editora, 1991.

- A glorificação.

São Paulo: Próton Editora, 1987.

PACHECO, Cláudia Bernhardt

de Souza. ABC da trilogia ana-

lítica: psicanálise integral. São

Paulo: Próton Editora. 1986. Dis-

ponível em: $<$ http://amicaru.com.

br/ebooks/ebook161.pdf> Acesso

em: 14 ago. 2017.

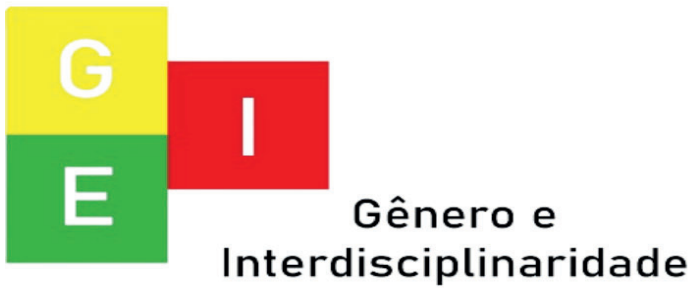

